\title{
1 Marine atmospheric corrosion of Al-Mg joints by friction stir blind riveting
}

2 Shengxi Li, Haris Khan, Lloyd H. Hihara*, Jingjing Li*

3 Department of Mechanical Engineering, University of Hawaii at Manoa, Honolulu, Hawaii

496822, USA

$5 \quad$ *Corresponding author: Tel.: +1 808956 3679; Fax: +1 8089562373.

6 E-mail: hihara@hawaii.edu (L.H.Hihara), lj8@hawaii.edu (J.J.Li),

8 Abstract

9 This paper investigated the atmospheric corrosion behavior of Al-Mg friction stir blind riveting 10 joints exposed at a severe marine test environment. Besides the severe corrosion that occurred on 11 Mg alloy AZ31B-H23, Al alloy 5754-O also corroded in the coupled region because of the alkaline 12 condition generated by the cathodic reaction inside of the crevice. The highly alkaline environment, 13 however, passivated $\mathrm{Mg}$ deep inside the crevice. The corrosion products on Mg were identified 14 as magnesium carbonates and that on $\mathrm{Al}$ was mainly gibbsite, which was an unusual corrosion 15 product of $\mathrm{Al}$ exposed to atmospheric conditions.

17 Keywords: A. Aluminum alloy; A. Magnesium alloy; B. IR spectroscopy; B. XRD; C. Alkaline 18 corrosion; C. Crevice corrosion

\section{Introduction}

The joining of dissimilar light metals is of increasing demand in the automotive industry for

22 weight reduction and tailored properties. However, the joining of dissimilar metals was limited

23 by traditional fusion welding method which cannot be applied in welding of different metals 
24 having vast discrepancy in melting temperatures and may generate brittle intermetallics [1,2].

25 Friction stir blind riveting (FSBR) is a new mechanical dissimilar material joining method

26 developed by General Motors in 2011 [3], where work materials are softened by the friction stir

27 process to facilitate rivet penetration. FSBR has been successfully applied to the joining of various

28 similar and dissimilar metallic materials, such as Al-Al [4-8], Mg-Al [5], Steel-Mg [9, 10], Al-

29 CFRP (carbon fiber reinforced plastics) [11], and CFRP-CFRP [12]. These emerging research

30 activities have suggested that FSBR is suitable for joining various metallic and nonmetallic

31 materials that result in joints having superior mechanical properties.

32 In addition to FSBR, other mechanical riveting methods, such as self-piercing riveting [13],

33 friction self-piercing riveting [14, 15], and friction stir riveting [16, 17], have also been

34 investigated for joining dissimilar materials. Most of the research, however, focused on process

35 optimization and mechanical behavior of the joints. Very limited research has been reported on

36 the corrosion behavior of these mechanical joints, which is a potential application issue for

37 dissimilar-material joints because of the possibility of galvanic corrosion and crevice corrosion at

38 the joint interface. The galvanic corrosion between the dissimilar material couples have been

39 widely studied in saline environments [18-24]. In these couples, the less noble material usually

40 experiences severe corrosion and the more noble material is protected. However, it was found in

41 the present work that the galvanic couple between $\mathrm{Al}$ and $\mathrm{Mg}$ behaves differently from

42 conventional understandings when a crevice forms between the two materials.

43 The Mg-Al dissimilar joints were selected in the present work because of great interests in the

44 automobile industry. While $\mathrm{Al}$ alloys have found a wide range of applications as lightweight and

45 high-strength structural materials, $\mathrm{Mg}$ alloys are also gaining interests as they are considered as

46 the lightest structural metallic materials (approximately 34\% lighter than $\mathrm{Al}$ ) and provide an 
attractive high strength to weight ratio for automotive applications. However, $\mathrm{Mg}$ alloys can be used in a few automotive parts [25] but not in others because of the limits in their mechanical properties, which therefore, requires the joining of $\mathrm{Mg}$ with other structural materials, such as Al. Besides the specific choice of the materials, the selection of a severe marine environment for exposure tests was due to the large presence of airborne salt particles in such environment [26, 27] and their great influence on the corrosion behavior of metallic materials [28-32].

The present study aims to 1) identify the various types of corrosion products that formed in the

54 Al-Mg FSBR joint exposed in a marine environment, and 2) elucidate the corrosion mechanism

55 through the characterization of corrosion products. The results will enhance the understanding of 56 corrosion behavior not only in FSBR joints but also in other mechanical joints constituted with

57 dissimilar metals.

\section{2. Experimental}

\subsection{Materials and FSBR joining}

60 The raw materials used were Mg AZ31B-H23 and Al 5754-O with chemical compositions 61 shown in Table 1. Fig. 1 illustrates the FSBR process for joining the Mg and Al sheets. The Al-

$62 \mathrm{Mg}$ FSBR joints were formed on a computer numerical control (CNC) machining center (model:

63 Bridgeport Discovery 308) using $1 \mathrm{~mm}$ thick $\mathrm{Mg}$ sheets and $3 \mathrm{~mm} \mathrm{Al} \mathrm{sheets.} \mathrm{Each} \mathrm{work} \mathrm{piece}$ 64 was $38 \mathrm{~mm}$ wide and $127 \mathrm{~mm}$ long. The overlap region had a size of $38 \mathrm{~mm} \times 38 \mathrm{~mm}$. The blind 65 rivet with a diameter of $6.4 \mathrm{~mm}$ was made of mild steel with zinc coating. The spindle speed was $665000 \mathrm{rpm}$ and the feed rate was $120 \mathrm{~mm} / \mathrm{min}$.

\subsection{Outdoor exposure}

68 The Al-Mg FSBR joints (in triplicate) including the rivets were exposed to a severe marine 69 test site located in the Marine Corps Base Hawaii (MCBH) in Kaneohe, Hawaii. This test site is 
70 maintained by the Hawaii Corrosion Laboratory and is considered a severe marine site with regards

71 to corrosion rates. The test site is located within 40 meters of a shoreline with waves breaking

72 consistently throughout the year. The average temperature and relative humidity are $23.6{ }^{\circ} \mathrm{C}$ and

$7377 \%$, respectively. The average chloride $\left(\mathrm{Cl}^{-}\right)$deposition rate was $2900 \mathrm{mg} / \mathrm{m}^{2} /$ day and the sulfate

$74\left(\mathrm{SO}_{4}{ }^{2-}\right)$ deposition rate was $390 \mathrm{mg} / \mathrm{m}^{2} /$ day, which were determined using the conventional dry

75 chloride candle method. The corroded joints were retrieved to the laboratory after 6-month

76 exposure for characterization. All three joints showed similar corrosion characteristics, however,

77 only one was characterized.

$78 \quad 2.3$ Corroded sample characterization

79 The corrosion products inside the crevice were revealed by pulling the joint to fracture using a

80 tensile machine. The surfaces of the corroded $\mathrm{Mg}$ and $\mathrm{Al}$ sheets were first characterized using a

81 JEOL JXA-8500F field emission scanning electron microscope (FE-SEM) with energy dispersive

82 spectroscopy (EDS) capability. Then, corrosion products were scraped from the $\mathrm{Al}$ and $\mathrm{Mg}$ sheets

83 and ground into fine powders using an agate pestle and mortar. The powder samples were

84 characterized with Fourier transform infrared spectroscopy (FTIR, Jasco FT/IR 4100) and powder

85 X-ray diffraction (XRD, Rigaku MiniFlex ${ }^{\mathrm{TM}}$ II) to identify the compositions of the corrosion 86 products.

87 The corroded Al sheet was also chemically cleaned using the procedures and solutions

88 described in ISO 8407: 2009 [33]. Three pristine Al sheets were also cleaned together with the

89 corroded sample. Multiple cleaning cycles were employed until the mass loss of the corroded

90 sample between cleaning cycles was equal to, or less than, the average mass loss of the pristine

91 samples. The cleaned sample was then characterized using the same FE-SEM.

92 2.4 Microstructural characterization 
The $\mathrm{Mg}$ and $\mathrm{Al}$ sheets that were in contact with the rivet were sectioned from the Al-Mg FSBR

94 joint using a low-speed diamond saw for microstructural characterization. The sectioned samples

95 were mounted in epoxy resin (BUEHLER Epoxicure); ground with 600 and 1200 grit SiC grinding

96 paper; and polished with 9.0, 3.0, and $1.0 \mu \mathrm{m}$ polycrystalline diamond suspensions (METADI

97 SUPREME, BUEHLER). The Mg sample was polished with isopropanol as a lubricant. After

98 polishing, the samples were ultrasonically cleaned in isopropanol for $5 \mathrm{~min}$ and dried under cold 99 air.

100 The polished samples, especially the regions that were in close contact with the rivet, were first 101 characterized using FE-SEM. Then, the samples were etched to reveal grain structures. The Mg 102 sample was etched using an Acetic Picral reagent $[34,35]$ to reveal grain boundaries. The grain 103 boundaries of the Al sample were revealed using the Baker's etching method [36, 37]. The Al 104 sample was oxidized in a solution consisting of $5 \mathrm{ml} \mathrm{HBF} 4(48 \%$, Sigma-Aldrich) in $200 \mathrm{ml}$ water 105 at a current of $0.2 \mathrm{~A} / \mathrm{cm}^{2}$ for $40-80$ seconds. Then, the grain structure of the etched/oxidized 106 samples were observed under an optical microscope (AxioPlan, Zeiss). Notice that the grain 107 structure of the oxidized Al sample was observed with polarized light plus a sensitive tint filter.

\section{3. Results and discussion}

$109 \quad 3.1$ Microstructure of the jointed materials

110 Fig. 2 shows the microstructures of the $\mathrm{Al}$ and $\mathrm{Mg}$ sheets in regions that are in close contact 111 with the galvanized steel rivet. Many strips of white particles were found on both $\mathrm{Al}$ (Fig. 2b and 112 c) and Mg (Fig. 2d and e). EDS elemental analysis of these white particles confirms that $\mathrm{Zn}$ was 113 infused into both $\mathrm{Al}$ and $\mathrm{Mg}$ after the FSBR process (Table 2). The widths of the Zn-contaminated 114 regions are in a range of approximately $50-150 \mu \mathrm{m}$ on both $\mathrm{Al}$ and $\mathrm{Mg}$. 
Fig. 3 shows the grain structures of $\mathrm{Mg}$ and $\mathrm{Al}$ in the FSBR-affected regions ( $\mathrm{b}$ and $\mathrm{d}$ ) as

116 compared to those of the base materials (a and c). It can be seen that the FSBR process refined

117 the grains in both $\mathrm{Mg}$ and $\mathrm{Al}$ near the rivet owing to the coupled thermomechnical effect generated

118 from the frictional stir penetration process [38]. The widths of grain-refined regions in $\mathrm{Mg}$ and $\mathrm{Al}$

119 are approximately $100-150 \mu \mathrm{m}$ and $50-80 \mu \mathrm{m}$, respectively. Notice that the etching of $\mathrm{Al}$ in the

120 refined region (Fig. 3d) did not result in well-defined grains due to the corrosion of $\mathrm{Zn}$ particles

121 (that were infused into Al during FSBR) in the acidic etching solution.

1223.2 Corrosion characteristics and morphology

123 Fig. 4a shows the images of the coupled sides of $\mathrm{Mg}$ and $\mathrm{Al}$ sheets after being separated by

124 tensile test. Severe corrosion occurred in most regions on Mg (e.g., location 1 in Fig. 4a), but not

125 in regions surrounding the rivet (e.g., location 2 in Fig. 4a) within the crevice of the joint. SEM

126 images (Fig. 4b1 and b2) from the corroded regions illustrate typical porous morphology of $\mathrm{Mg}$

127 corrosion products [39], and those from the uncorroded regions (Fig. 4c1 and c2) even showed

128 some original scratches from material fabrication or handling. On Al, significant corrosion did

129 not occur on the regions outside of the joints (Fig. 4e). However, the central region of the coupled

130 area (within the dotted line on Al in Fig. 4a) was covered by a thick layer of yellowish-brown

131 corrosion products, which looked distinct from the white corrosion products on Mg. Notice that

132 the yellowish-brown corrosion products on $\mathrm{Mg}$ (marked by thick solid arrows in Fig. 4a) was

133 actually from Al (marked by thick open arrows in Fig. 4a). An SEM image (Fig. 4d) of the

134 yellowish-brown corrosion product further indicated that it was visually different from the porous

135 corrosion products on $\mathrm{Mg}$ (Fig. 4b2), possibly indicating that it came from the corrosion of Al.

136 Table 3 summaries the EDS results from different locations (1-4) in Fig. 4a. Location 1 (Table

137 3) has a very high content of $\mathrm{O}$, suggesting that $\mathrm{Mg}$ was significantly corroded in uncoupled 
138 regions. As compared to location 1 in Fig. 4a, location 2 has a much lower $\mathrm{O}$ content and a much

139 higher Mg content (Table 3), implying the possible absence of corrosion on the coupled side of $140 \mathrm{Mg}$ in regions near the rivet. The $\mathrm{O}$ in uncorroded $\mathrm{Mg}$ is likely from the surface oxide films. The 141 high contents of $\mathrm{Al}$ and $\mathrm{O}$ at location 3 (Table 3) indicate the occurrence of corrosion on the 142 coupled side of $\mathrm{Al}$ in regions close to the rivet. However, the uncoupled $\mathrm{Al}$ (e.g., location 4 in Fig.

143 4a) shows much less $\mathrm{O}$ but more $\mathrm{Al}$ (Table 3 ) as compared to $\mathrm{Al}$ in the center of the coupled area. 144 Therefore, the uncoupled Al experienced only slight corrosion.

145 After collecting the yellowish-brown corrosion products on $\mathrm{Al}$, the rivet was removed by 146 cutting it apart together with the Al sheet using a low speed diamond saw (black dashed line in 147 Fig. 4a). The sectioned aluminum sheet was chemically cleaned according to ISO 8407: 2009 [33].

148 The cleaned sample (Fig. 5a) clearly reveals that severe corrosion occurred on Al in the center of 149 the coupled region (inside the dotted line) but not on the edge (outside of the dotted line). Both 150 visual observation (Fig. 5a) and low-magnification SEM observation (Fig. 5b1) suggest that 151 corrosion was generally uniform on a macro scale with no large corrosion pits (i.e., pits larger than $1521 \mathrm{~mm}$ ). A high-magnification SEM image (Fig. 5b2) from the corroded region shows only micron153 sized corrosion pits. The micron-sized corrosion pits are also seen in the SEM images (Fig. 5c1 154 and c2) from the intermediate region (along the dotted line in Fig. 2a) between the corroded and 155 uncorroded regions. Some scattered regions with insignificant corrosion (remnants of the original 156 Al surface, marked by arrows in Fig. 5c2) are also present in the intermediate region. The SEM 157 images (Fig. $5 \mathrm{~d} 1$ and $\mathrm{d} 2$ ) from the edge of the coupled region on $\mathrm{Al}$ show that most of the $\mathrm{Al}$ 158 surface is pristine and only mild corrosion occurred with the formation of micron-sized pits. 
Fig. 6a presents a typical FTIR spectrum obtained from the corrosion products formed on $\mathrm{Mg}$,

161 either in the coupled region or the uncoupled area because they have the same spectrum. The 162 peaks at $716,745,796,854,882,1113,1426$, and $1479 \mathrm{~cm}^{-1}$ can be assigned to hydromagnesite $163\left(\mathrm{Mg}_{5}\left(\mathrm{CO}_{3}\right)_{4}(\mathrm{OH})_{2} \cdot 4 \mathrm{H}_{2} \mathrm{O}\right)$, which has been identified as the corrosion products on $\mathrm{Mg}$ after 164 atmospheric corrosion $[40,41]$. However, it was reported that dypingite $\left(\mathrm{Mg}_{5}\left(\mathrm{CO}_{3}\right)_{4}(\mathrm{OH})_{2} \cdot 5 \mathrm{H}_{2} \mathrm{O}\right)$ 165 also has similar peaks as those shown in Fig. 6a [42]. Therefore, hydromagnesite and dypingite 166 could coexist in the corrosion products on $\mathrm{Mg}$, which is corroborated by XRD analysis in the 167 following section. The peak at $876 \mathrm{~cm}^{-1}$ and a possible hidden peak at approximately $1447 \mathrm{~cm}^{-1}$ 168 indicated the presence of magnesite $\left(\mathrm{MgCO}_{3}\right)$ [40]. Notice that a prominent peak for brucite $169\left(\mathrm{Mg}(\mathrm{OH})_{2}\right)$ at $3699 \mathrm{~cm}^{-1}[40]$ is absent from Fig. 6a, which suggests that the corrosion products on $170 \mathrm{Mg}$ exposed to a marine environment are mainly carbonate compounds. The yellowish-brown 171 corrosion products formed on $\mathrm{Al}$ in the central coupled region (close to the rivet) showed a 172 spectrum with major peaks at $663,747,800,914,970,1022$, and $3444 \mathrm{~cm}^{-1}$ (Fig. 6b), which match 173 well with those of gibbsite $\left(\gamma-\mathrm{Al}(\mathrm{OH})_{3}\right)[43,44]$. Therefore, FTIR analysis demonstrated that the 174 corrosion products on $\mathrm{Al}$ are mainly due to the corrosion of $\mathrm{Al}$, corroborating the EDS results in 175 the above section.

176 Fig. 7a and $\mathrm{b}$ presents the XRD patterns of the corrosion products formed on $\mathrm{Mg}$ and $\mathrm{Al}$ in the 177 Al-Mg FSBR joint, respectively. Most of the XRD peaks in Fig. 7a can be assigned to either 178 hydromagnesite (PDF Card No.: 00-025-0513) or dypingite (PDF Card No.: 00-023-1218) [39, $17945-48]$. The peak at $8.16^{\circ}$ corroborates the existence of dypingite since hydromagnesite does not 180 have such a peak. The majority of the XRD peaks in Fig. 7b, especially those with strong 181 intensities, are caused by gibbsite (PDF Card No.: 00-012-0460) [49-51], indicating gibbsite as the 182 major component of the corrosion products on Al. The peak at approximately $18.66^{\circ}$ might have 
183 originated from the other two polymorphs of $\mathrm{Al}(\mathrm{OH})_{3}$, bayerite (PDF Card No.: 01-077-0250) and

184 nordstrandite (PDF Card No.: 00-018-0050) [52], the concentration of which were lower than that

185 of gibbsite. The two weak peaks at $11.64^{\circ}$ and $23.4^{\circ}$ are not identified. Notice that the XRD peaks

186 in Fig. 7b have much stronger intensities than those in Fig. 7a, which implies that the corrosion

187 product on $\mathrm{Al}$ has a higher degree of crystallinity than that on $\mathrm{Mg}$. Generally, the identification of

188 gibbsite on $\mathrm{Al}$ and magnesium carbonates on $\mathrm{Mg}$ using XRD agrees well with previous FTIR 189 results.

\subsection{Corrosion mechanism}

191 When $\mathrm{Mg}$ is coupled to $\mathrm{Al}$, galvanic corrosion occurs on $\mathrm{Mg}$ because $\mathrm{Mg}$ is less noble as 192 compared to Al. In this case, $\mathrm{Al}$ serves as the cathode at which cathodic reactions occur. Due to 193 the highly confined environment inside the crevice, $\mathrm{O}_{2}$ should not be readily accessible to the 194 crevice. Therefore, it is reasonable to assume that the cathodic reactions are $\mathrm{H}_{2}$ evolution (Eq. 1) 195 inside of the crevice and oxygen reduction (Eq. 2) just outside of the crevice (Fig. 8a).

$1962 \mathrm{H}_{2} \mathrm{O}+2 \mathrm{e}^{-} \rightarrow 2 \mathrm{OH}^{-}+\mathrm{H}_{2} \quad(1)$

$197 \quad \mathrm{O}_{2}+2 \mathrm{H}_{2} \mathrm{O}+4 \mathrm{e}^{-} \rightarrow 4 \mathrm{OH}^{-}(2)$

198 The accumulation of $\mathrm{OH}^{-}$ions increases the local $\mathrm{pH}$ because of the cathodic reaction inside 199 the crevice. Since Al corrodes in the environment with a pH higher than approximately 8.5 [53], 200 the increase of $\mathrm{pH}$ in the crevice resulted in the corrosion of $\mathrm{Al}$ (Fig. 8b). It has been reported 201 that the corrosion product of $\mathrm{Al}$ in a pH higher than 9 is gibbsite (Fig. 8c) [54], which is 202 corroborated in the present study by FTIR and XRD analyses. Notice that gibbsite is not usually 203 found as the corrosion product of $\mathrm{Al}$ exposed to various atmospheric conditions [55-58]. The 204 reason for the formation of gibbsite in the present study was the high $\mathrm{pH}$ environment in the 205 confines of the crevice. After the dissolution of Al initiated inside the crevice, the major cathodic 206 reaction was oxygen reduction occurring on $\mathrm{Al}$ in the uncoupled regions. 
The increase of $\mathrm{pH}$ inside the crevice, if up to approximately 11.4 will passivate $\mathrm{Mg}$ [53].

208 Since it was observed that corrosion did not occur on Mg deep inside the crevice or in the thinnest

209 crevice (Fig. $4 \mathrm{c} 1$ and $\mathrm{c} 2$ ), it is believed that the local $\mathrm{pH}$ rose to 11.4. The Pourbaix diagram of

$210 \mathrm{Mg}[53]$ also shows that $\mathrm{Mg}$ would spontaneously passivate at potentials greater than the $\mathrm{Mg}$

211 equilibrium potential, indicating that $\mathrm{Mg}$ could therefore passivate in the crevice where the

212 corrosion potential would be more positive than the $\mathrm{Mg}$ equilibrium potential due to polarization

213 of hydrogen evolution. The extremely high $\mathrm{pH}$ in the crevice was likely caused by the generation

214 of a large amount of $\mathrm{OH}^{-}$ions in a highly confined space. In addition, the excess $\mathrm{OH}^{-}$ions

215 electrostatically repelled other anions (i.e., $\mathrm{Cl}^{-}$) from the crevice to maintain charge neutrality,

216 which also enhances passivation of $\mathrm{Mg}$. The EDS results (Table 3) showed that $\mathrm{Cl}$ was

217 undetectable on $\mathrm{Mg}$ in the crevice (location 2) but present on $\mathrm{Mg}$ outside of the crevice (location

218 1). Similar behavior has been observed for $\mathrm{Mg}$-SiC couples in chloride-containing environments

219 where SEM and EDS analysis showed minimal corrosion and low $\mathrm{Cl}^{-}$-concentration within the

220 crevice, and significant corrosion and high $\mathrm{Cl}^{-}$-concentration outside of the crevice [59].

221 The initial corrosion product formed on $\mathrm{Mg}$ is believed to be brucite $\left(\mathrm{Mg}(\mathrm{OH})_{2}\right)$ (Fig. 8b) in

222 an environment where $\mathrm{NaCl}$ and high humidity are present $[60,61]$. Brucite will then react with

$223 \mathrm{CO}_{2}$ from the atmosphere, forming magnesium carbonates hydrates (Fig. 8c), which are the

224 primary corrosion product of $\mathrm{Mg}$ exposed to atmospheric corrosion conditions [47, 60, 61].

225 It is worth to mention that the effects of microstructural changes in $\mathrm{Mg}$ and $\mathrm{Al}$ (caused by the

226 FSBR process) on the crevice corrosion behavior can be excluded, because it is believed that the

227 regions with microstructural alterations were not exposed to electrolyte. These regions have a

228 maximum width of approximately $150 \mu \mathrm{m}$, as shown in Figs. 2 and 3. However, the deformation

229 zone (marked by a dashed rectangle in Fig. 9a), which prevents the electrolyte inside the crevice 
230 from reaching the rivet/Mg and rivet/Al interfaces, has a width of approximately $0.5-1 \mathrm{~mm}$. In

231 addition, the close contact between the rivet and the $\mathrm{Mg}$ and $\mathrm{Al}$ sheets (marked by dashed arrows

232 in Fig. 9b) hinders the electrolyte access to the rivet hole. As the corrosion of $\mathrm{Al}$ initiates inside

233 the crevice, the Al/electrolyte interface (region 3 in Fig. 9b) will move towards the rivet hole.

234 However, the formation of corrosion product (i.e., $\left.\mathrm{Al}(\mathrm{OH})_{3}\right)$ inside the crevice (Fig. 9c) would

235 have quickly clogged the tip of the crevice and thus stopped the movement of electrolyte towards

236 the rivet hole. Notice that bulk electrolyte was not usually present on the samples exposed in

237 atmospheric conditions (except during rain). However, we believe that only a small amount of

238 water is needed to fill the crevice and that amount of water is readily available in the severe marine

239 test site where the $\mathrm{Al}-\mathrm{Mg}$ couples were exposed. In addition, it is believed that the crevice areas

240 can retain moisture much longer than open surfaces since it takes longer for moisture to evaporate

241 from the crevice [62]. In an environment with relative humidity values in the range of

242 approximately $67 \%$ to $94 \%$, any region that is exposed to sea salt will be wet (or with the presence

243 of electrolyte) since the critical relative humidities for $\mathrm{NaCl}$ and $\mathrm{MgCl}_{2}$ are $\sim 75 \%$ and $\sim 33 \%$,

244 respectively, and both species are present in seawater.

245 Finally, it is believed that the corrosion caused by the Zn-coated carbon steel rivet also does

246 not affect the crevice corrosion behavior discussed above. The first type of rivet-related corrosion

247 is the self-corrosion of the rivet (regions 1 and 4 in Fig. 9b) due to low corrosion resistivity of 248 galvanized steel in severe marine environment. The second type of rivet-related corrosion is 249 galvanic corrosion, which accelerates the corrosion of $\mathrm{Mg}$ near the rivet/Mg interface (region 2 in 250 Fig. 9b) as well as the corrosion of the rivet close to the rivet/Al interface (region 4 in Fig. 9b).

251 However, all these types of corrosion do not alter the crevice corrosion behavior because they 252 occur separately from the corrosion inside the crevice. 
The present study implies that when $\mathrm{Al}$ is coupled to Mg using FSBR, not only has $\mathrm{Mg}$ to be

254 protected, but also Al especially when a crevice forms in between the coupled materials. This

255 implication also applies to other cases when Al is mechanically coupled to less noble metallic

256 materials and crevices form in between them.

\section{4. Conclusions}

258 1. Outdoor exposure tests showed that when Al was coupled to Mg using FSBR, both crevice and 259 external corrosion (outside of the crevice) occurred. Within the crevice, $\mathrm{Mg}$ passivated and 260 significant corrosion was observed on Al. A high $\mathrm{pH}$ environment was created within the 261 crevice due to the hydrogen-evolution cathodic reaction that generates $\mathrm{OH}^{-}$. The excess $262 \mathrm{OH}^{-}$also repelled $\mathrm{Cl}^{-}$from the crevice and enhanced the passivation of $\mathrm{Mg}$. Since aluminum 263 oxide is amphoteric, Al lost passivation and corroded in the high $\mathrm{pH}$ environment of the crevice. 264 On the outside of the crevice, corrosion on $\mathrm{Al}$ was minimal and corrosion on $\mathrm{Mg}$ was 265 substantial.

2. A combination of FTIR and XRD facilitated the identification of the corrosion products on $\mathrm{Mg}$

267 as hydromagnesite, dypingite, and magnesite, which are common corrosion products formed 268 on $\mathrm{Mg}$ exposed to atmospheric conditions. The abnormal identification of gibbsite as the 269 corrosion product on $\mathrm{Al}$ exposed to marine atmospheric conditions is caused by the high $\mathrm{pH}$ 270 environment inside the crevice formed during FSBR process.

271 3. The findings add new knowledge to the crevice corrosion between mechanically jointed Al 272 and $\mathrm{Mg}$ sheets.

273

274 Acknowledgements 
275 This work was funded by the US National Science Foundation Civil, Mechanical and 276 Manufacturing Innovation (grant no.: 1363468, 1554748), and Office of the Under Secretary of 277 Defense (U.S. Air Force Academy, grant no.: FA7000-10-2-0010). The authors wish to thank Prof. 278 Craig Jensen in the Department of Chemistry at the University of Hawaii at Manoa for the help on 279 XRD measurements; Mr. Ryan Sugamoto of the Hawaii Corrosion Laboratory for outdoor 280 exposure tests; and Mr. Daniel Dunmire, Director, Corrosion Policy and Oversight, Office of the 281 Under Secretary of Defense.

282 


\section{References}

284 [1] M. Hansen, K. Anderko, Constitution of Binary Alloys, McGraw-Hill Book Company, Inc., 285 New York, 1958.

286 [2] S. Sundaresan, K.G.K. Murti, The formation of intermetallic phases in aluminium-austenitic 287 stainless steel friction welds, Mater. Forum, 17 (1994) 301-307.

288 [3] P.C. Wang, R. Stevenson, Friction stir rivet method of joining, U.S. Patent 7862271 B2, 2892011.

290 [4] D. Gao, U. Ersoy, R. Stevenson, P.-C. Wang, A new one-sided joining process for aluminum 291 alloys: Friction stir blind riveting, J. Manuf. Sci. Eng., 131 (2009) 061002-061002.

292 [5] S. Lathabai, V. Tyagi, D. Ritchie, T. Kearney, B. Finnin, Friction stir blind riveting: A novel 293 joining process for automotive light alloys, SAE Int. J. Mater. Manuf., 4 (2011) 589-601.

294 [6] J. Min, Y. Li, J. Li, B.E. Carlson, J. Lin, Mechanics in frictional penetration with a blind 295 rivet, J. Mater. Process. Technol., 222 (2015) 268-279.

296 [7] J. Min, J. Li, Y. Li, B.E. Carlson, J. Lin, W.-M. Wang, Friction stir blind riveting for 297 aluminum alloy sheets, J. Mater. Process. Technol., 215 (2015) 20-29.

298 [8] J. Min, J. Li, B.E. Carlson, Y. Li, J. Lin, Mechanical property of Al alloy joints by friction 299 stir blind riveting, Procedia Eng., 81 (2014) 2036-2041.

300 [9] C. Zhang, X. Wang, B. Li, A technological study on friction stir blind rivet jointing of 301 AZ31B magnesium alloys and high-strength DP600 steel, Adv. Mater. Res., 183-185 (2011) $302 \quad 1616-1620$.

303 [10] C. Zhang, B. Li, X. Wang, Lap joint properties of FSBRed dissimilar metals AZ31 Mg alloy 304 and DP600 high-strength steel with various parameters, Adv. Mater. Res., 228-229 (2011) 427305432. 
306 [11] J. Min, Y. Li, J. Li, B. Carlson, J. Lin, Friction stir blind riveting of carbon fiber-reinforced 307 polymer composite and aluminum alloy sheets, Int. J. Adv. Manuf. Technol. , 76 (2015) 14033081410.

309 [12] B. Croom, W.-M. Wang, J. Li, X. Li, Unveiling 3D deformations in polymer composites by 310 coupled micro X-ray computed tomography and volumetric digital image correlation, Exp.

311 Mech., (2016) 1-18.

312 [13] X. He, I. Pearson, K. Young, Self-pierce riveting for sheet materials: State of the art, J. 313 Mater. Process. Technol., 199 (2008) 27-36.

314 [14] Y. Li, Z. Wei, Z. Wang, Y. Li, Friction self-piercing riveting of aluminum alloy AA6061315 T6 to magnesium alloy AZ31B, J. Manuf. Sci. Eng., 135 (2013) 061007-061007.

316 [15] B. Wang, C. Hao, J. Zhang, H. Zhang, A new self-piercing riveting process and strength 317 evaluation, J. Manuf. Sci. Eng., 128 (2005) 580-587.

318 [16] J. Altmeyer, J.F. dos Santos, S.T. Amancio-Filho, Effect of the friction riveting process 319 parameters on the joint formation and performance of Ti alloy/short-fibre reinforced polyether 320 ether ketone joints, Mater. Des., 60 (2014) 164-176.

321 [17] S.T. Amancio-Filho, J.F. dos Santos, Joining of polymers and polymer-metal hybrid 322 structures: Recent developments and trends, Polym. Eng. Sci., 49 (2009) 1461-1476.

323 [18] G. Song, B. Johannesson, S. Hapugoda, D. StJohn, Galvanic corrosion of magnesium alloy 324 AZ91D in contact with an aluminium alloy, steel and zinc, Corros. Sci., 46 (2004) 955-977. 325 [19] K.B. Deshpande, Validated numerical modelling of galvanic corrosion for couples:

326 Magnesium alloy (AE44)-mild steel and AE44-aluminium alloy (AA6063) in brine solution, 327 Corros. Sci., 52 (2010) 3514-3522. 
328 [20] K.B. Deshpande, Effect of aluminium spacer on galvanic corrosion between magnesium and

329 mild steel using numerical model and SVET experiments, Corros. Sci., 62 (2012) 184-191.

330 [21] Z. Feng, G.S. Frankel, C.A. Matzdorf, Quantification of accelerated corrosion testing of

331 coated AA7075-T6, J. Electrochem. Soc., 161 (2013) C42-C49.

332 [22] Z. Feng, G.S. Frankel, Galvanic test panels for accelerated corrosion testing of coated Al

333 alloys: Part 2 - measurement of galvanic interaction, Corrosion, 70 (2013) 95-106.

334 [23] Z. Feng, J. Boerstler, G.S. Frankel, C.A. Matzdorf, Effect of surface pretreatment on

335 galvanic attack of coated Al alloy panels, Corrosion, 71 (2015) 771-783.

336 [24] Z. Feng, G.S. Frankel, W.H. Abbott, C.A. Matzdorf, Galvanic attack of coated Al alloy

337 panels in laboratory and field exposure, Corrosion, (2015) 342-355.

338 [25] M.K. Kulekci, Magnesium and its alloys applications in automotive industry, Int J Adv

339 Manuf Technol, 39 (2007) 851-865.

340 [26] S. Li, Marine atmospheric corrosion initiation and corrosion products characterization, in:

341 Mechanical Engineering, University of Hawai'i at Manoa, Honolulu, 2010, pp. 205.

342 [27] S. Li, L.H. Hihara, Aerosol salt particle deposition on metals exposed to marine

343 environments: a study related to marine atmospheric corrosion, J. Electrochem. Soc., 161 (2014)

344 C268-C275.

345 [28] S.X. Li, L.H. Hihara, Atmospheric corrosion initiation on steel from predeposited $\mathrm{NaCl}$ salt 346 particles in high humidity atmospheres, Corros. Eng., Sci. and Tech., 45 (2010) 49-56.

347 [29] S. Li, L. Hihara, A micro-Raman spectroscopic study of marine atmospheric corrosion of

348 carbon steel: The effect of akaganeite, J. Electrochem. Soc., 162 (2015) C495-C502.

349 [30] S. Li, L.H. Hihara, In situ Raman spectroscopic study of $\mathrm{NaCl}$ particle-induced marine

350 atmospheric corrosion of carbon steel, J. Electrochem. Soc., 159 (2012) C147-C154. 
351 [31] S. Li, L.H. Hihara, In situ Raman spectroscopic identification of rust formation in Evans'

352 droplet experiments, Electrochem. Commun., 18 (2012) 48-50.

353 [32] S. Li, L.H. Hihara, Atmospheric-Corrosion Electrochemistry of $\mathrm{NaCl}$ Droplets on Carbon

354 Steel, J. Electrochem. Soc., 159 (2012) C461-C468.

355 [33] ISO 8407:2009 Corrosion of metals and alloys -- Removal of corrosion products from

356 corrosion test specimens, (2009).

357 [34] A.E. Coy, F. Viejo, P. Skeldon, G.E. Thompson, Susceptibility of rare-earth-magnesium

358 alloys to micro-galvanic corrosion, Corros. Sci., 52 (2010) 3896-3906.

359 [35] R. Arrabal, A. Pardo, M.C. Merino, M. Mohedano, P. Casajús, K. Paucar, G. Garcés, Effect

360 of $\mathrm{Nd}$ on the corrosion behaviour of AM50 and AZ91D magnesium alloys in $3.5 \mathrm{wt} . \% \mathrm{NaCl}$

361 solution, Corros. Sci., 55 (2012) 301-312.

362 [36] K. Gopala Krishna, K. Sivaprasad, T.S.N. Sankara Narayanan, K.C. Hari Kumar, Localized

363 corrosion of an ultrafine grained $\mathrm{Al}-4 \mathrm{Zn}-2 \mathrm{Mg}$ alloy produced by cryorolling, Corros. Sci., 60

364 (2012) 82-89.

365 [37] F. Eckermann, T. Suter, P.J. Uggowitzer, A. Afseth, A.J. Davenport, B.J. Connolly, M.H.

366 Larsen, F.D. Carlo, P. Schmutz, In situ monitoring of corrosion processes within the bulk of

367 AlMgSi alloys using X-ray microtomography, Corros. Sci., 50 (2008) 3455-3466.

368 [38] J. Min, J. Li, Y. Li, B.E. Carlson, J. Lin, Affected Zones in an Aluminum Alloy Frictionally

369 Penetrated by a Blind Rivet, ASME J. Manuf. Sci. Eng., 138 (2015) 054501-054501.

370 [39] Z. Cui, X. Li, K. Xiao, C. Dong, Atmospheric corrosion of field-exposed AZ31 magnesium

371 in a tropical marine environment, Corros. Sci., 76 (2013) 243-256.

372 [40] M. Jönsson, D. Persson, D. Thierry, Corrosion product formation during $\mathrm{NaCl}$ induced

373 atmospheric corrosion of magnesium alloy AZ91D, Corros. Sci., 49 (2007) 1540-1558. 
374 [41] M. Jönsson, D. Persson, C. Leygraf, Atmospheric corrosion of field-exposed magnesium 375 alloy AZ91D, Corros. Sci., 50 (2008) 1406-1413.

376 [42] J.H. Canterford, G. Tsambourakis, B. Lambert, Some observations on the properties of 377 dypingite, $\mathrm{Mg}_{5}\left(\mathrm{CO}_{3}\right)_{4}(\mathrm{OH})_{2} \cdot 5 \mathrm{H}_{2} \mathrm{O}$, and related minerals, Mineral. Mag., 48 (1984) 437-442.

378 [43] H. Elderfield, J.D. Hem, Development of crystalline structure in aluminum hydroxide 379 polymorphs on aging, Mineral. Mag., 39 (1973) 89-96.

380 [44] G.Y. Chao, J. Baker, A.P. Sabina, A.C. Roberts, Doyleite, a new polymorph of $\mathrm{Al}(\mathrm{OH})_{3}$, 381 and its relationship to bayerite, gibbsite and nordstrandite, Can. Mineral., 23 (1985) 21-28. 382 [45] R. Arrabal, E. Matykina, A. Pardo, M.C. Merino, K. Paucar, M. Mohedano, P. Casajús, 383 Corrosion behaviour of AZ91D and AM50 magnesium alloys with Nd and Gd additions in 384 humid environments, Corros. Sci., 55 (2012) 351-362.

385 [46] J. Liao, M. Hotta, S.-i. Motoda, T. Shinohara, Atmospheric corrosion of two field-exposed 386 AZ31B magnesium alloys with different grain size, Corros. Sci., 71 (2013) 53-61.

387 [47] M. Esmaily, M. Shahabi-Navid, J.E. Svensson, M. Halvarsson, L. Nyborg, Y. Cao, L.G. 388 Johansson, Influence of temperature on the atmospheric corrosion of the Mg-Al alloy AM50, 389 Corros. Sci., 90 (2015) 420-433.

390 [48] R. Arrabal, B. Mingo, A. Pardo, E. Matykina, M. Mohedano, M.C. Merino, A. Rivas, A. 391 Maroto, Role of alloyed Nd in the microstructure and atmospheric corrosion of as-cast 392 magnesium alloy AZ91, Corros. Sci., 97 (2015) 38-48.

393 [49] T. Tsuchida, N. Ichikawa, Mechanochemical phenomena of gibbsite, bayerite and boehmite 394 by grinding, React. Solids, 7 (1989) 207-217.

395 [50] S. Korablov, M.A.M. Ibrahim, M. Yoshimura, Hydrothermal corrosion of TiAlN and CrN 396 PVD films on stainless steel, Corros. Sci., 47 (2005) 1839-1854. 
397 [51] L. Soler, J. Macanás, M. Muñoz, J. Casado, Aluminum and aluminum alloys as sources of 398 hydrogen for fuel cell applications, J. of Power Sources, 169 (2007) 144-149.

399 [52] L. Soler, A.M. Candela, J. Macanás, M. Muñoz, J. Casado, In situ generation of hydrogen 400 from water by aluminum corrosion in solutions of sodium aluminate, J. of Power Sources, 192 401 (2009) 21-26.

402 [53] M. Pourbaix, Atlas of Electrochemical Equilibria in Aqueous Solutions, National 403 Association of Corrosion Engineers, 1974.

404 [54] K. Wefers, C. Misra, Oxides and hydroxides of aluminum, in: Alcoa Technical Paper No. 405 19, Revised, Alcoa Laboratories, Alcoa, Pittsburgh, 1987.

406 [55] C. Leygraf, T. Graedel, Atmospheric Corrosion, Wiley-Interscience, New York, 2000.

407 [56] D. de la Fuente, E. Otero-Huerta, M. Morcillo, Studies of long-term weathering of 408 aluminium in the atmosphere, Corros. Sci., 49 (2007) 3134-3148.

409 [57] D.B. Blücher, J.E. Svensson, L.G. Johansson, The influence of $\mathrm{CO}_{2}, \mathrm{AlCl}_{3} \cdot 6 \mathrm{H}_{2} \mathrm{O}$, $410 \mathrm{MgCl}_{2} \cdot 6 \mathrm{H}_{2} \mathrm{O}, \mathrm{Na}_{2} \mathrm{SO}_{4}$ and $\mathrm{NaCl}$ on the atmospheric corrosion of aluminum, Corros. Sci., 48 411 (2006) 1848-1866.

412 [58] R.E. Melchers, Bi-modal trend in the long-term corrosion of aluminium alloys, Corros. Sci., $41382(2014) 239-247$.

414 [59] R. Srinivasan, L.H. Hihara, Correlation of Laboratory and Field Exposure of Localized 415 Corrosion at Magnesium-Ceramic Interfaces, in: CORROSION 2015, NACE International, 416 Dallas, Texas, 2015.

417 [60] M. Shahabi-Navid, M. Esmaily, J.E. Svensson, M. Halvarsson, L. Nyborg, Y. Cao, L.G. 418 Johansson, $\mathrm{NaCl}$-induced atmospheric corrosion of the $\mathrm{MgAl}$ alloy $\mathrm{AM} 50$ - the influence of $419 \mathrm{CO}_{2}$, J. Electrochem. Soc., 161 (2014) C277-C287. 
420 [61] M. Esmaily, N. Mortazavi, J.E. Svensson, M. Halvarsson, D.B. Bluecher, A.E.W. Jarfors, 421 M. Wessen, L.G. Johansson, Atmospheric corrosion of Mg alloy AZ91D fabricated by a semi422 solid casting technique: The influence of microstructure, J. Electrochem. Soc., 162 (2015) C311$423 \mathrm{C} 321$.

424 [62] M. Morcillo, B. Chico, I. Díaz, H. Cano, D. de la Fuente, Atmospheric corrosion data of 425 weathering steels. A review, Corros. Sci., 77 (2013) 6-24.

426 


\section{Tables:}

$428 \quad$ Table 1

429 Chemical compositions (wt.\%) of the raw materials.

\begin{tabular}{ccccccccccc}
\hline Material & $\mathrm{Si}$ & $\mathrm{Fe}$ & $\mathrm{Mn}$ & $\mathrm{Zn}$ & $\mathrm{Cu}$ & $\mathrm{Ti}$ & $\mathrm{Cr}$ & $\mathrm{Ni}$ & $\mathrm{Al}$ & $\mathrm{Mg}$ \\
\hline $5754-\mathrm{O}$ & 0.4 & 0.4 & 0.5 & 0.2 & 0.1 & 0.15 & 0.03 & - & balance & 2.6 \\
$\mathrm{AZ31B}-\mathrm{H} 23$ & 0.009 & 0.004 & 0.28 & 0.9 & - & - & - & 0.0008 & 2.95 & balance \\
\hline
\end{tabular}

430

431 Table 2.

432 Elemental compositions (at.\%) of locations 1 and 2 in Fig. 2.

\begin{tabular}{cccc}
\hline Locations & $\mathrm{Zn}$ & $\mathrm{Mg}$ & $\mathrm{Al}$ \\
\hline 1 (on $\mathrm{Mg})$ & 34.62 & 60.13 & 5.25 \\
2 (on $\mathrm{Al})$ & 28.15 & 1.65 & 70.2 \\
\hline
\end{tabular}

433

434 Table 3

435 Elemental compositions (at.\%) of locations $1-4$ in Fig. 4a.

\begin{tabular}{lcccccccc}
\hline \multicolumn{1}{c}{ Locations } & $\mathrm{C}$ & $\mathrm{O}$ & $\mathrm{Na}$ & $\mathrm{Mg}$ & $\mathrm{Al}$ & $\mathrm{S}$ & $\mathrm{Cl}$ & $\mathrm{Zn}$ \\
\hline 1: $\mathrm{Mg}$, uncoupled & 17.20 & 61.44 & 0.85 & 15.69 & 2.44 & 0.19 & 1.81 & 0.39 \\
2: Mg, coupled & 3.73 & 8.54 & - & 85.64 & 1.69 & - & - & 0.31 \\
3: Al, coupled & 4.57 & 73.07 & 1.13 & 3.23 & 17.99 & - & - & - \\
4: Al, uncoupled & 6.54 & 13.49 & - & 2.90 & 74.04 & - & - & - \\
\hline
\end{tabular}




\section{Figure captions:}

438 Fig. 1. Illustration of the FSBR process [7]: (a) rotating blind rivet approaching the workpieces;

439 (b) frictional penetration of the rivet; (c) pulling out the mandrel; and (d) completion.

441 Fig. 2. Microstructures of the $\mathrm{Mg}$ and $\mathrm{Al}$ sheets adjacent to the rivet. Intermetallic particles are 442 marked by arrows. Unmarked black scale bars are $50 \mu \mathrm{m}$ and white scale bars are $2 \mu \mathrm{m}$.

444 Fig. 3. Microstructure comparisons between the base and after FSBR metals: (a and c) Grain 445 structures of $\mathrm{Mg}$ and $\mathrm{Al}$ base materials; ( $\mathrm{b}$ and d) grain structures of $\mathrm{Mg}$ and $\mathrm{Al}$ in the FSBR446 affected regions. Black scale bars are $10 \mu \mathrm{m}$ and white scale bars are $50 \mu \mathrm{m}$. The center 447 embedded figure indicates the observation locations of (a-d).

449 Fig. 4. (a) Images of the $\mathrm{Al}$ and $\mathrm{Mg}$ sheets separated from the Al-Mg FSBR joints by tensile test, 450 showing the growth of corrosion products on both sheets after 6-month exposure in a marine 451 environment; (b1, b2, c1, c2, d, and e) SEM images from different locations (1-4) in (a). The 452 dashed line indicates where the sample together with the rivet was sectioned. Black scale bars 453 are $100 \mu \mathrm{m}$ and white scale bars are $10 \mu \mathrm{m}$.

455 Fig. 5. (a) An image of the A1 sheet after chemical clearing; (b1, b2, c1, c2, d1, and d2) SEM 456 images from different locations (1-3) in (a). Black scale bars are $100 \mu \mathrm{m}$ and white scale bars are $457 \quad 10 \mu \mathrm{m}$.

459 Fig. 6. FTIR spectra obtained from the corrosion products (a) on $\mathrm{Mg}$ and (b) on $\mathrm{Al}$ in the $\mathrm{Al}-\mathrm{Mg}$ 460 BSBR joint. 
461 Fig. 7. XRD patterns of powder samples made from (a) corrosion product on $\mathrm{Mg}$ and (b) corrosion 462 product on $\mathrm{Al}$ in the coupled region.

463

464 Fig. 8. Schematic diagrams of the corrosion process inside the crevice between $\mathrm{Al}$ and $\mathrm{Mg}$ coupled 465 by FSBR.

466

467 Fig. 9. Schematic diagrams showing the various types of corrosion in the Al-Mg FSBR joints. 
Figure1

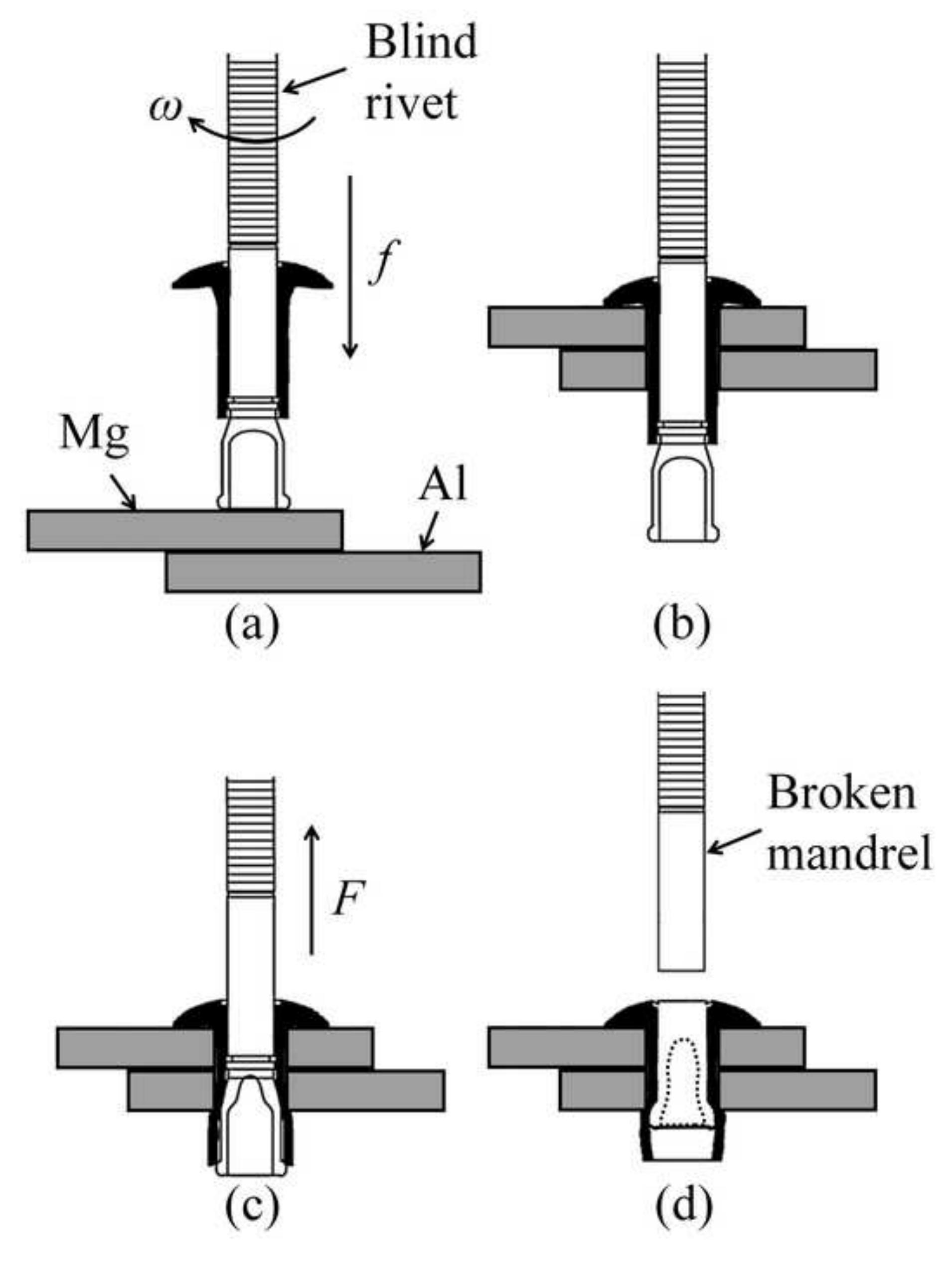

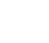

\begin{abstract}
Fing
\end{abstract}

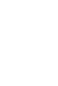

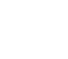

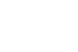

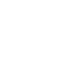

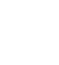

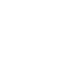




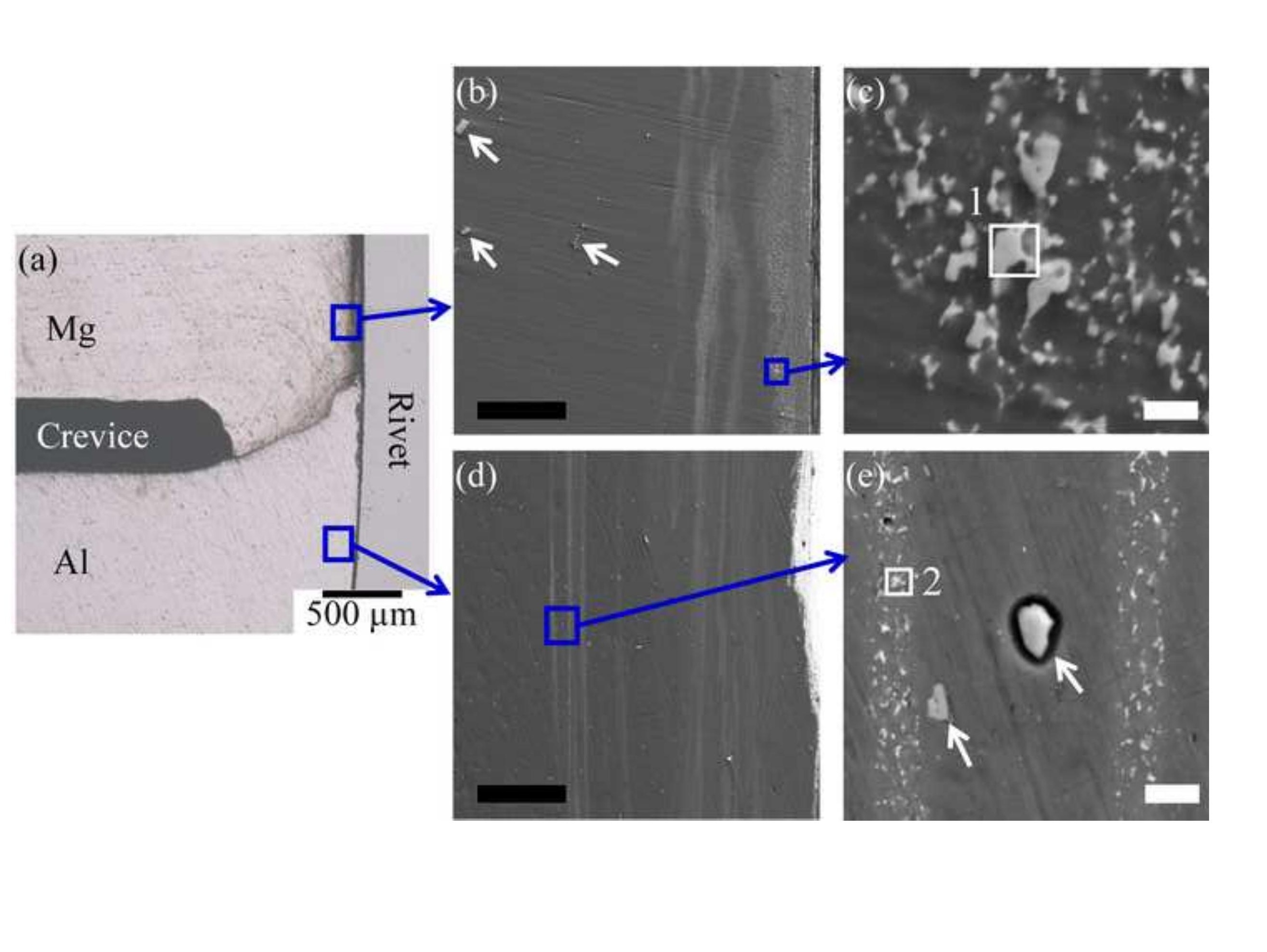

2
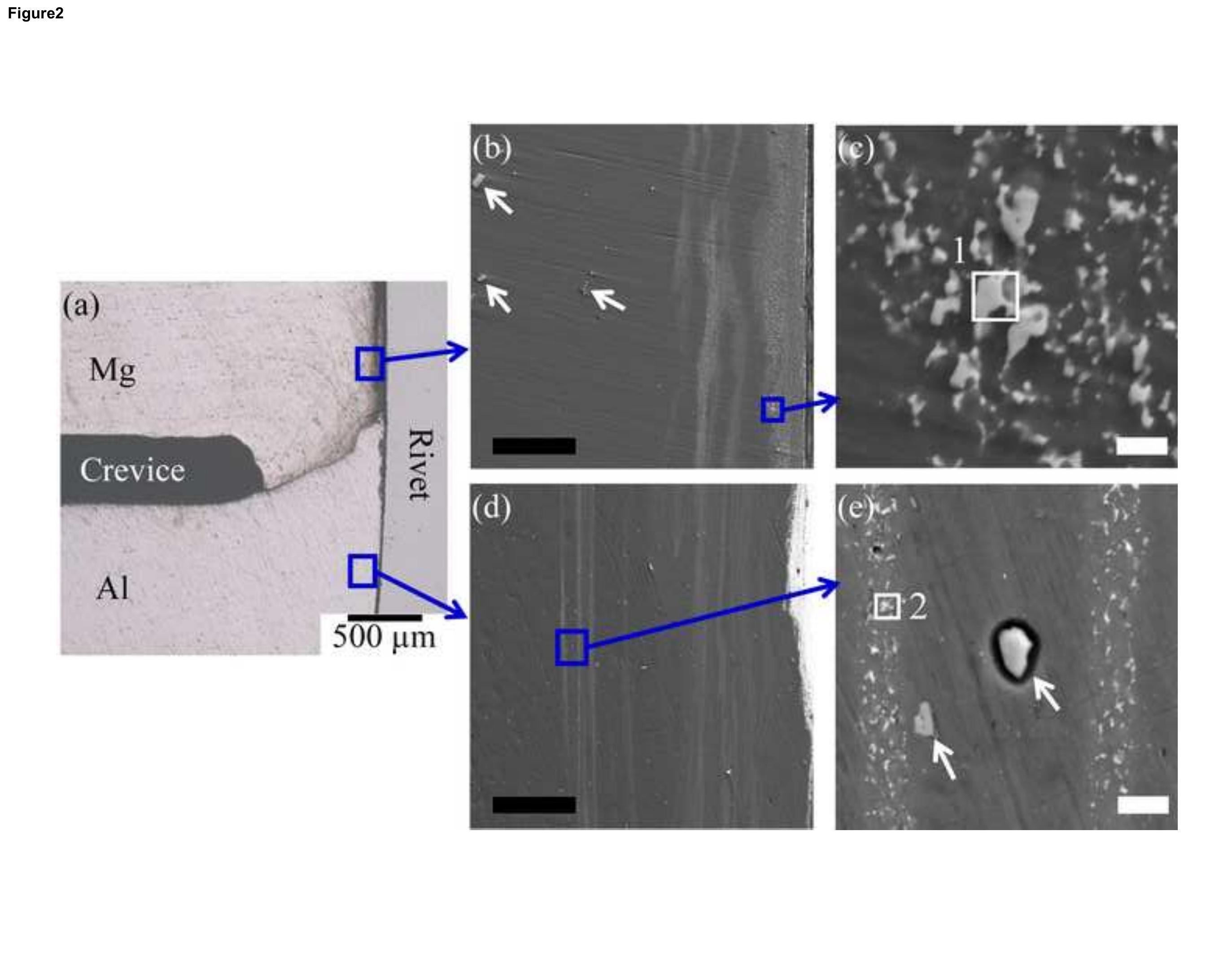


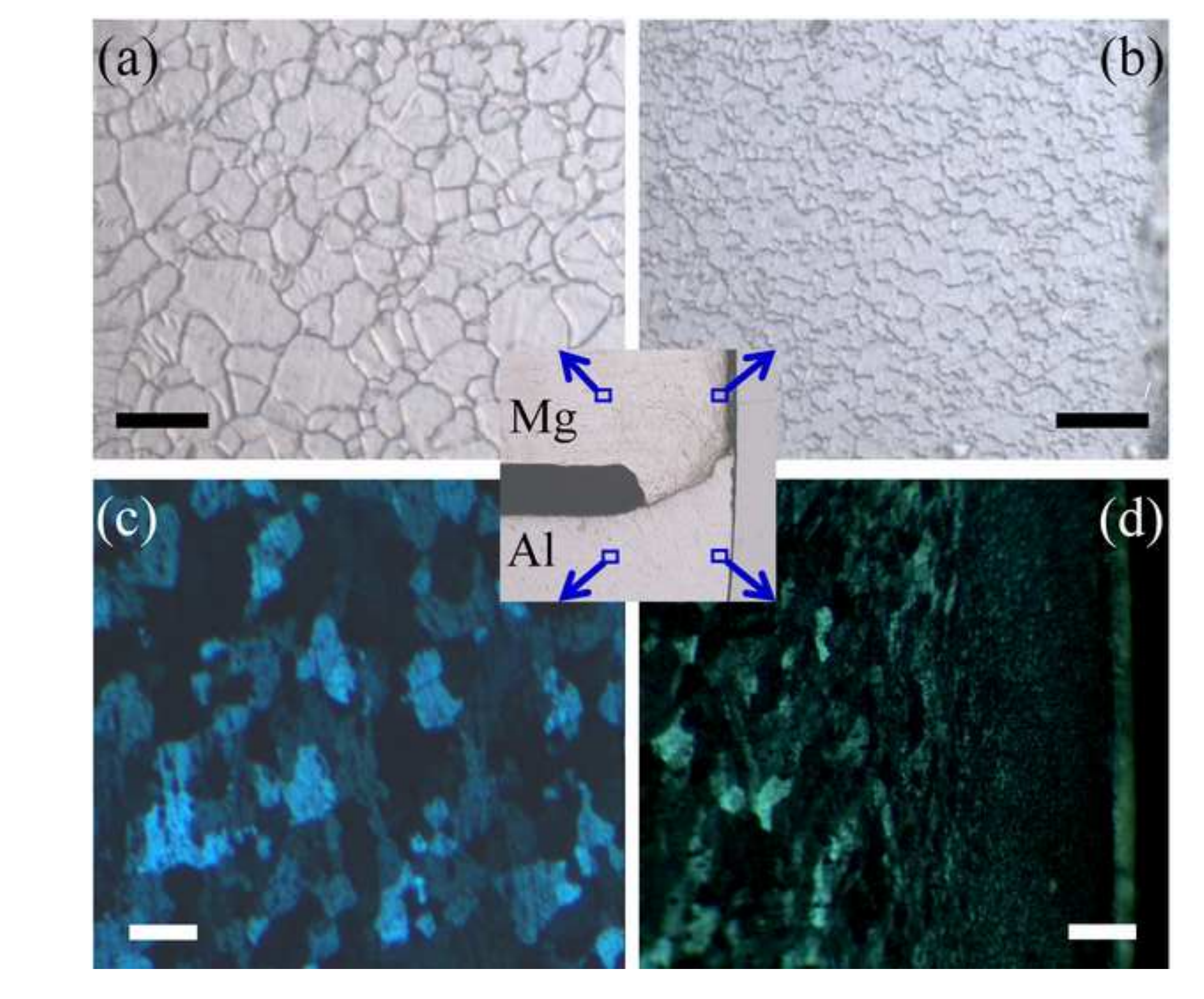

3
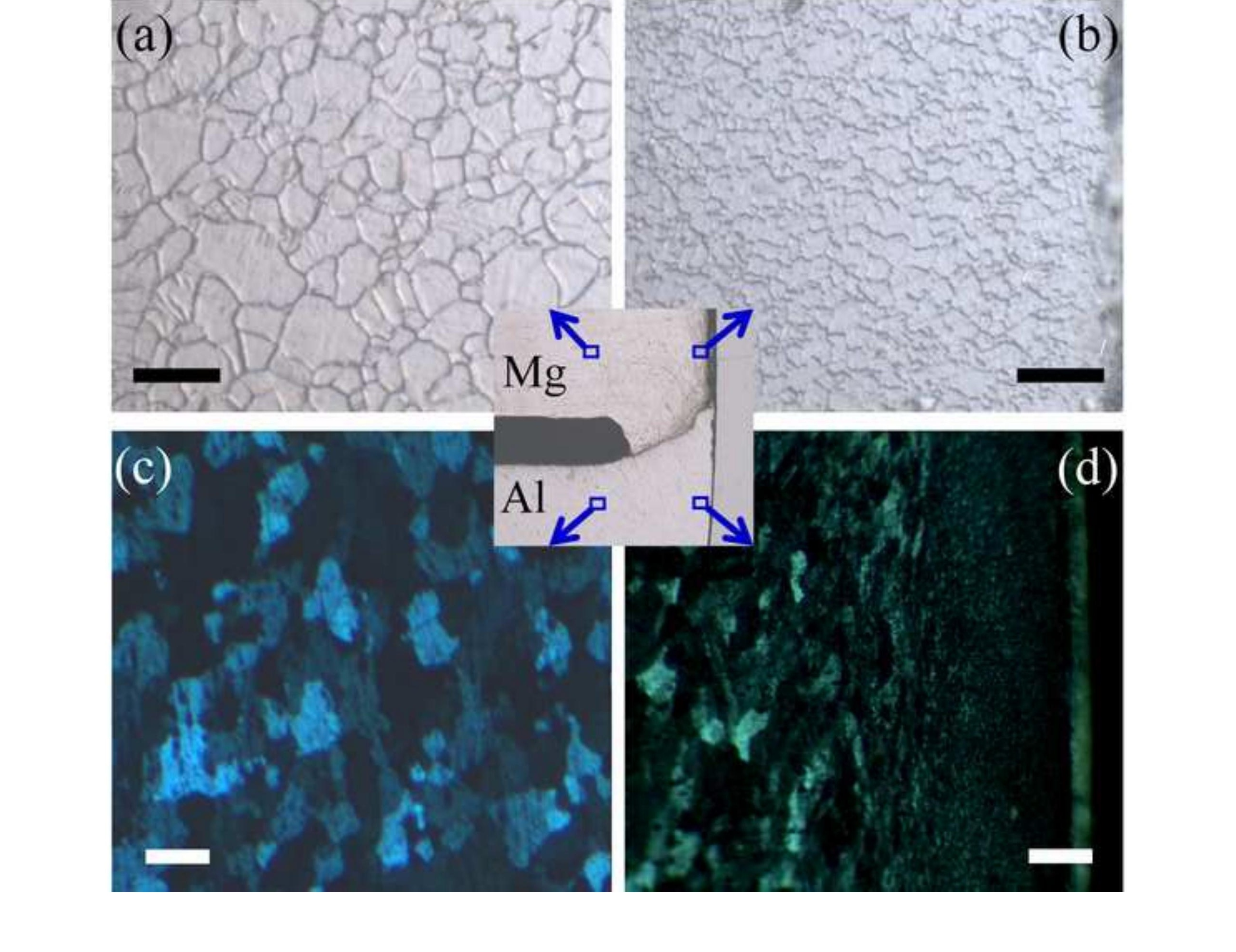

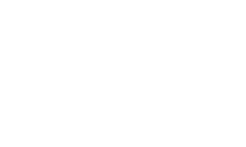
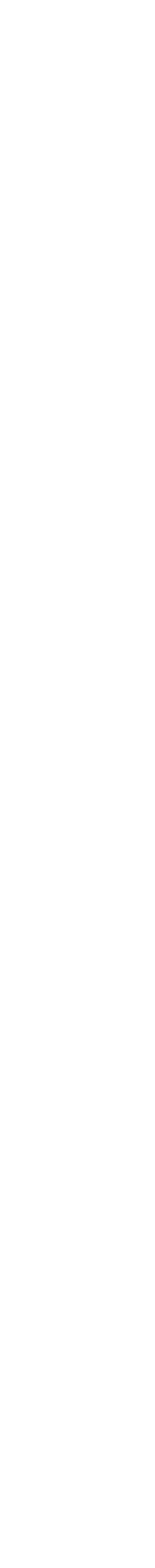
$\mathrm{Mg}$

$\mathrm{Al}$
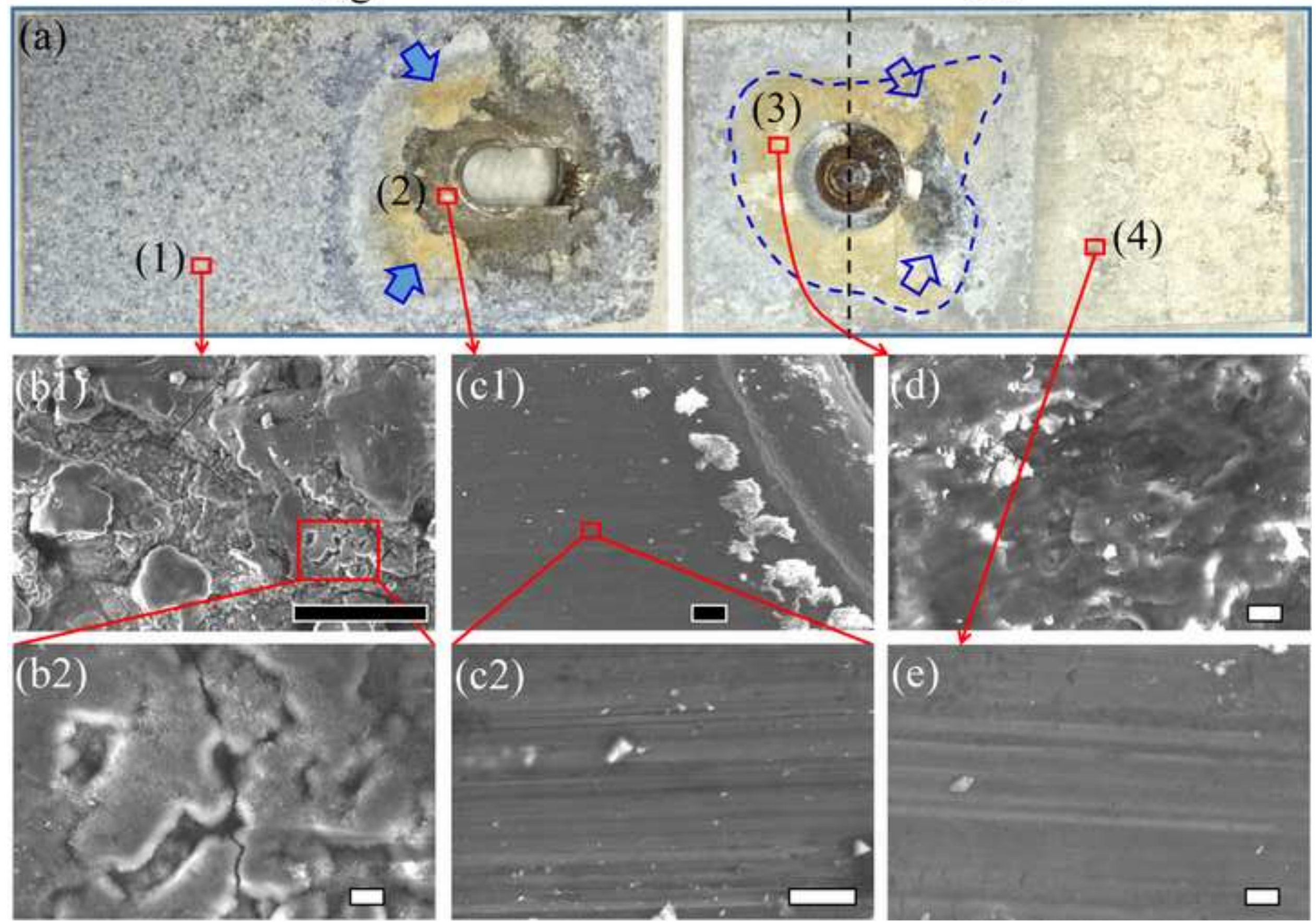

(e)

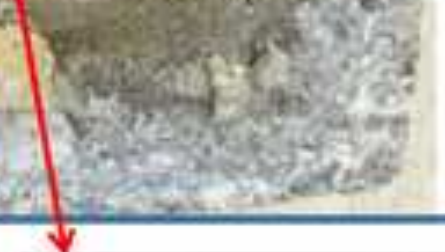

$\sum_{1} !$

문
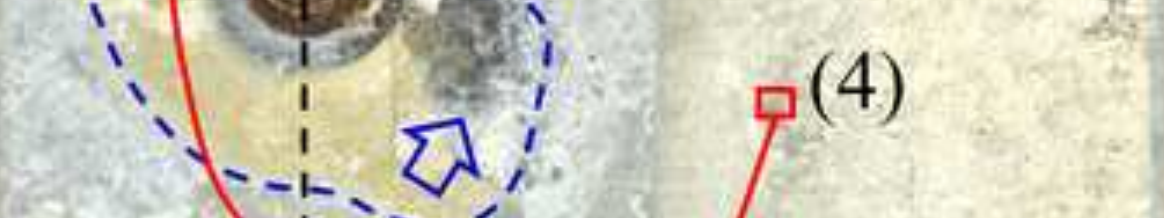

.

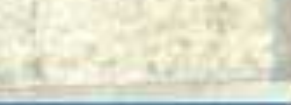

(c2)
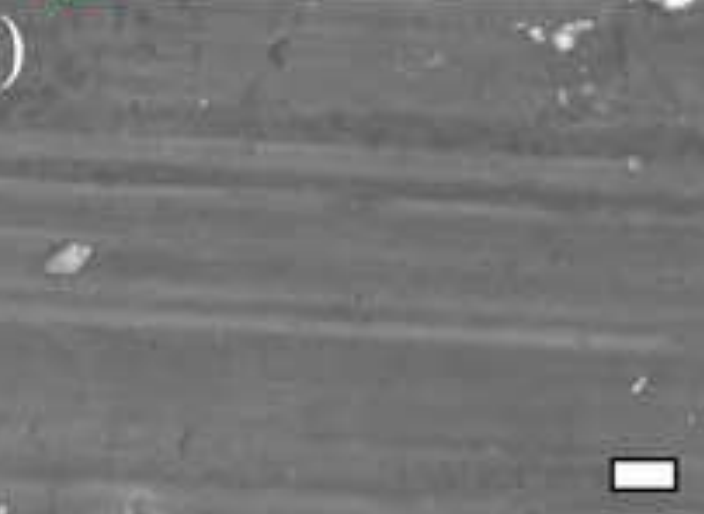


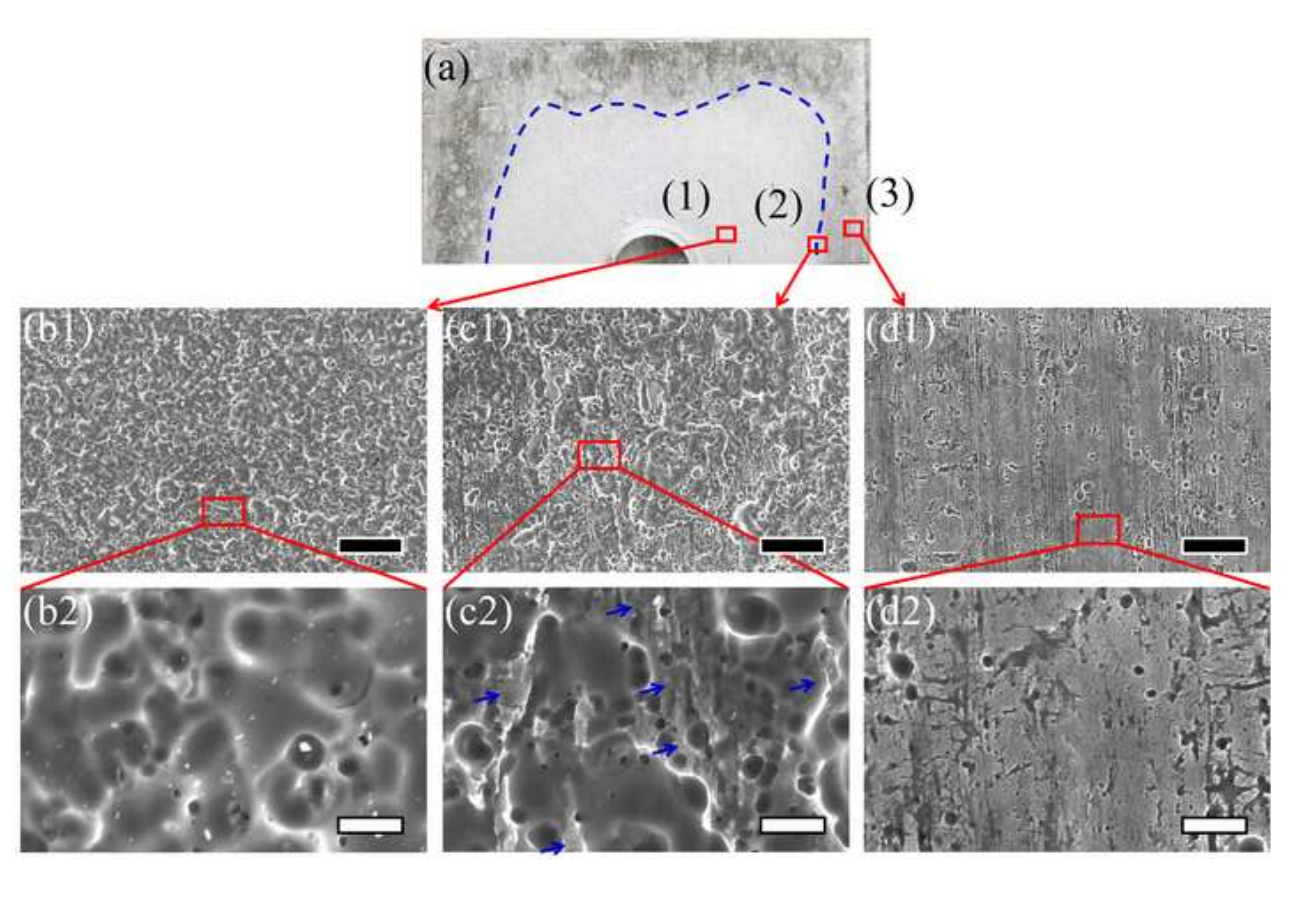

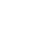

.

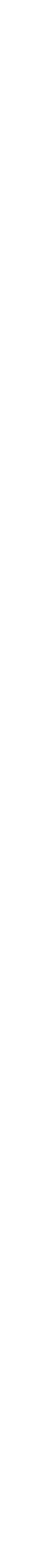




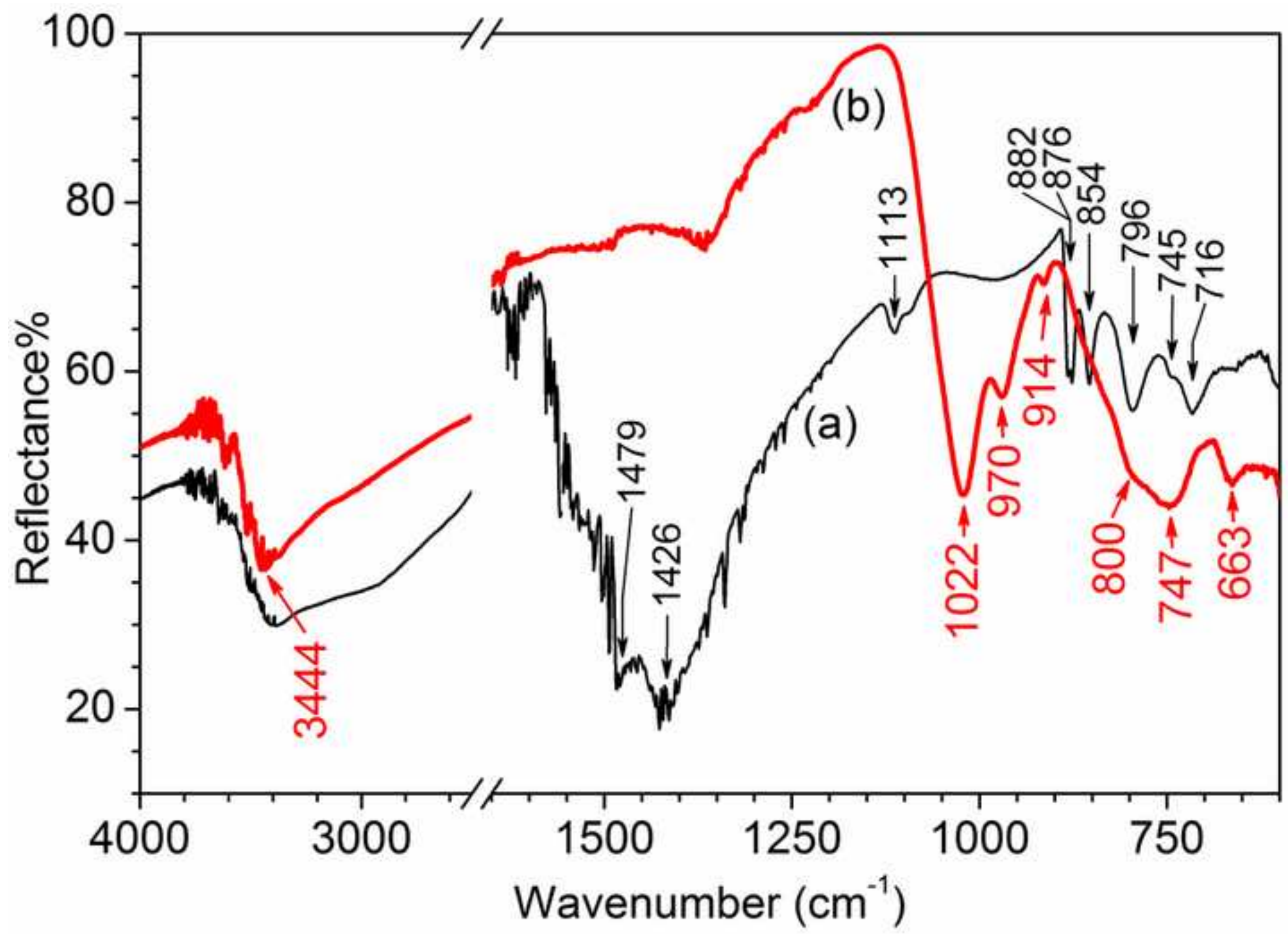



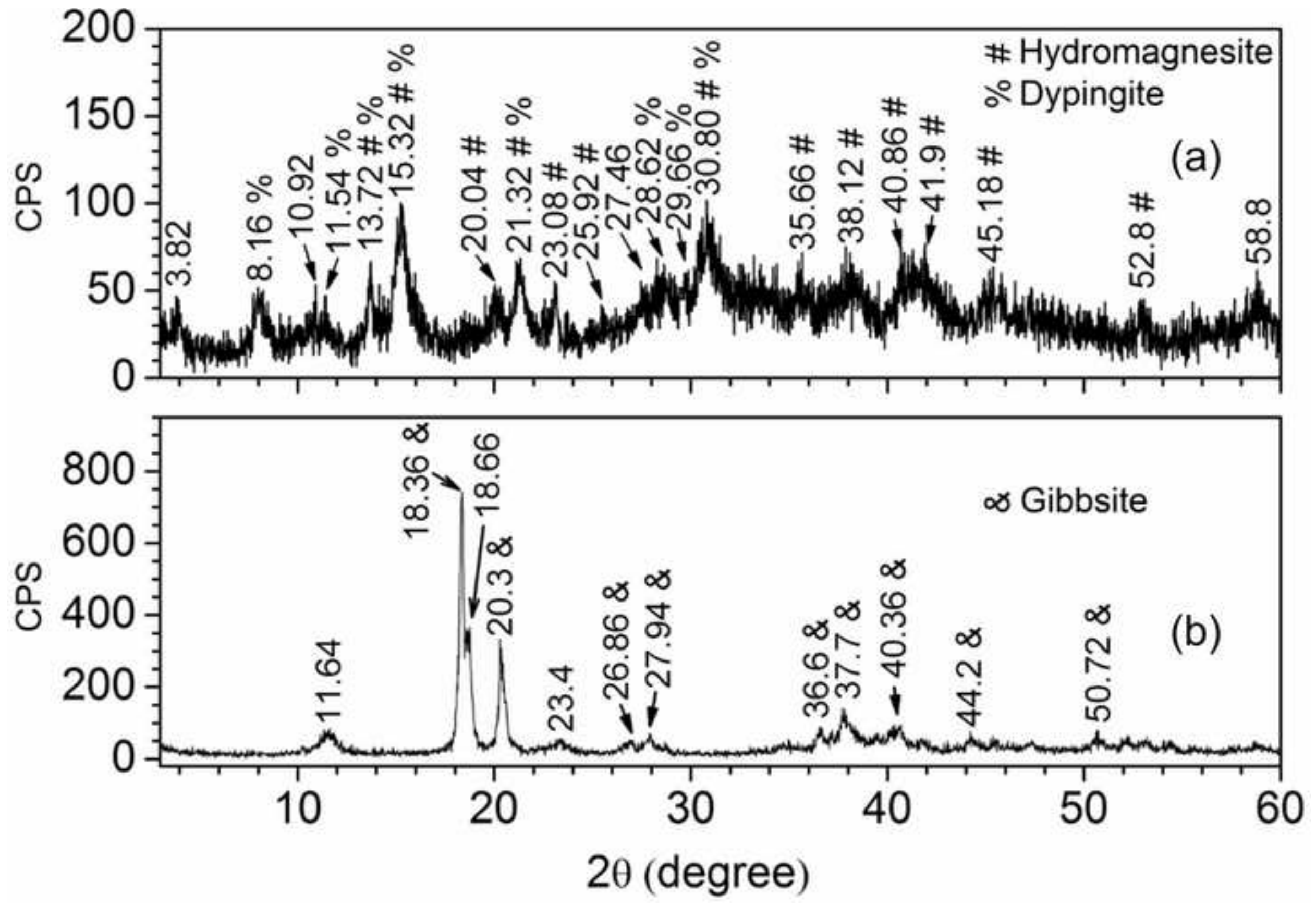
(a)

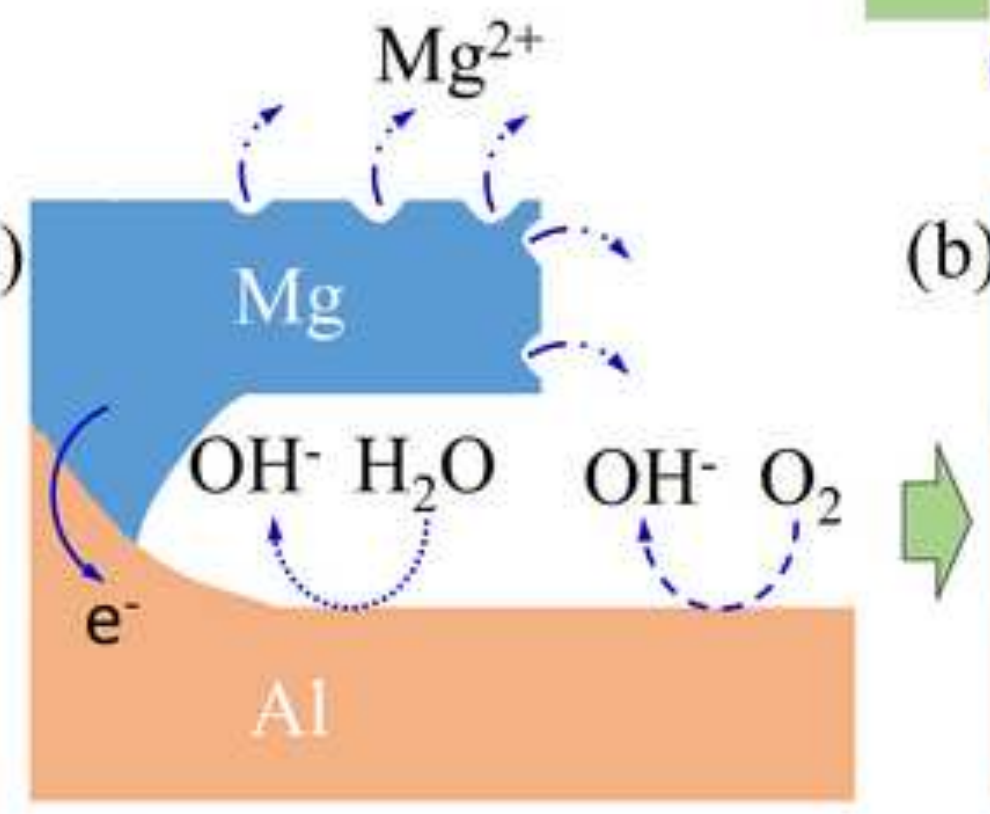

(d)

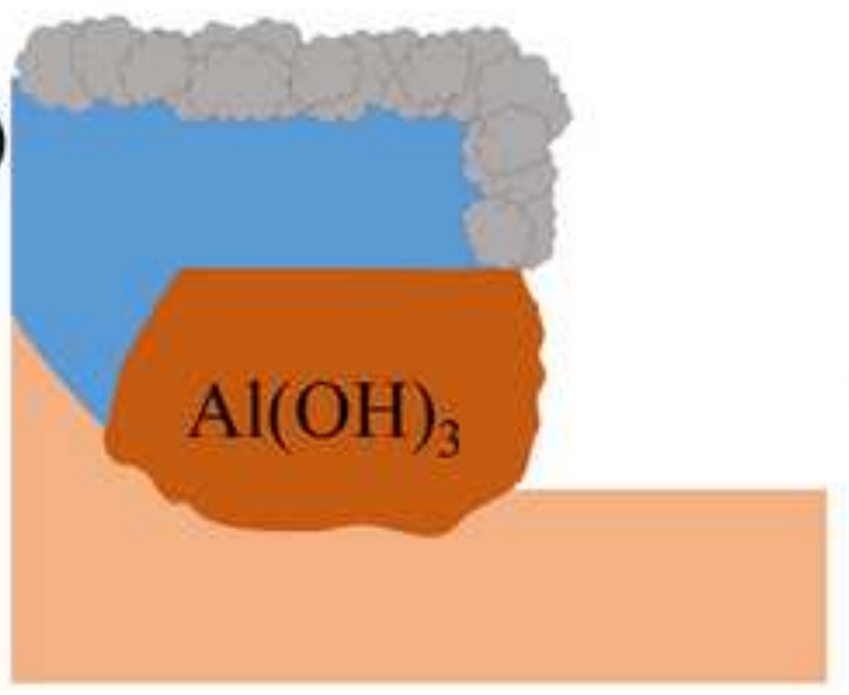

\section{Rivety}

\section{$\mathrm{Mg}$}

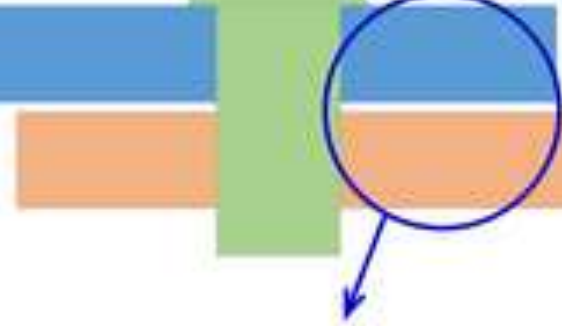

Al

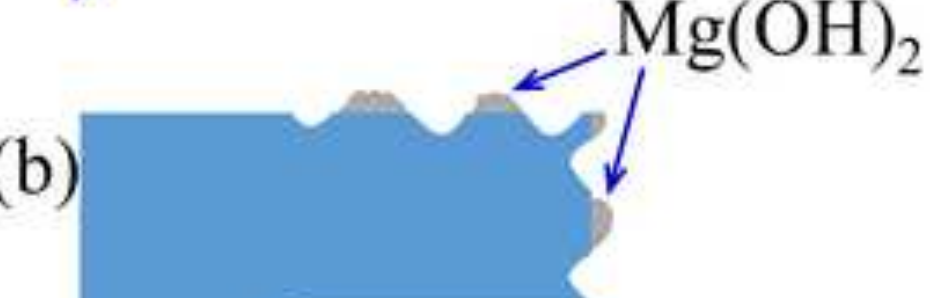

(c)

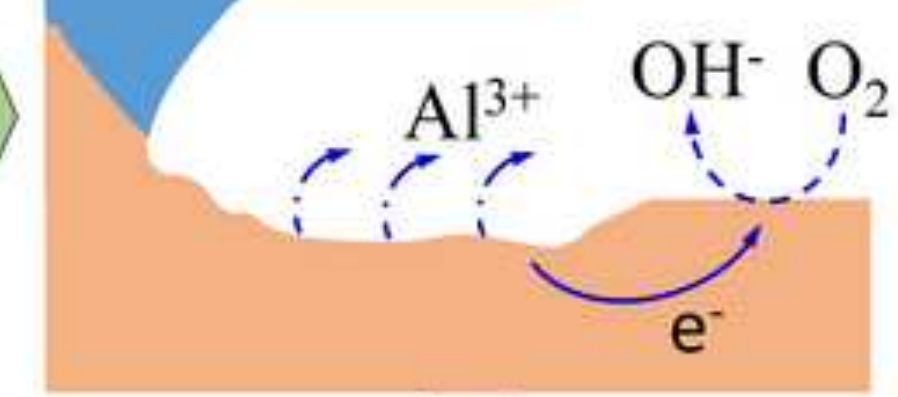

$\square$

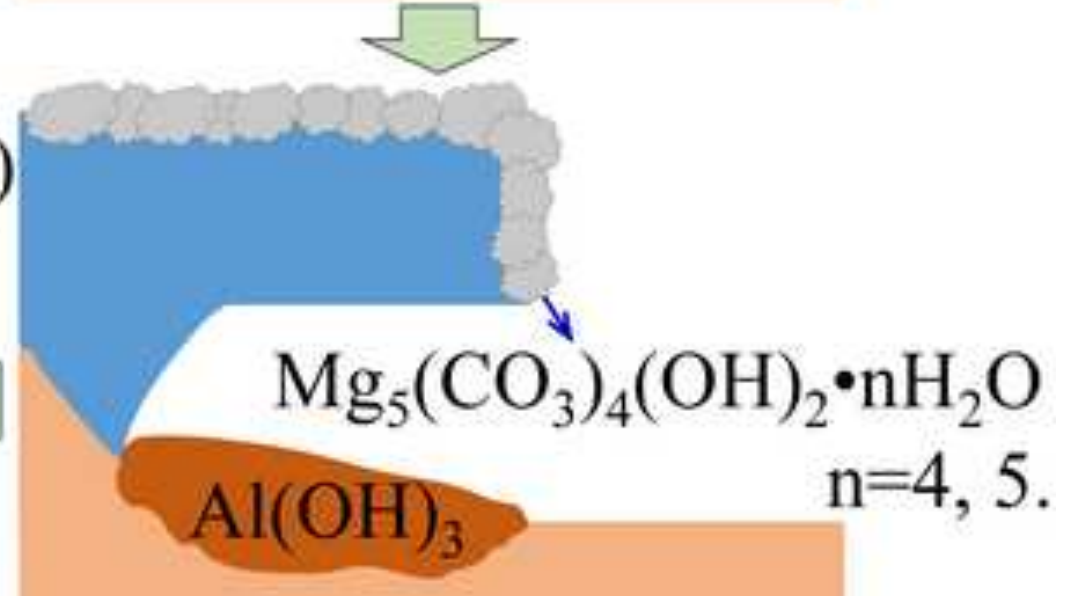




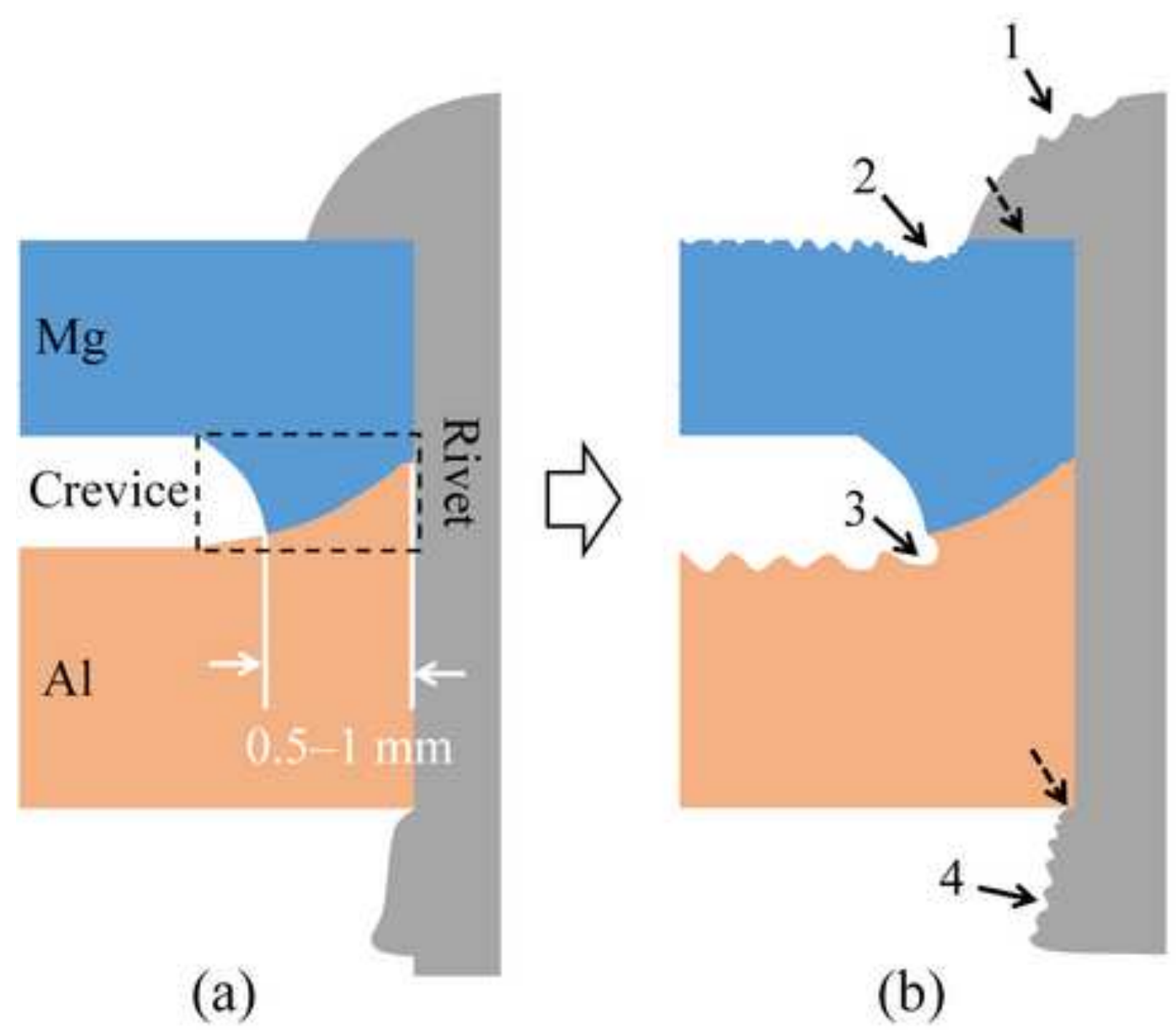

(a)

(b)

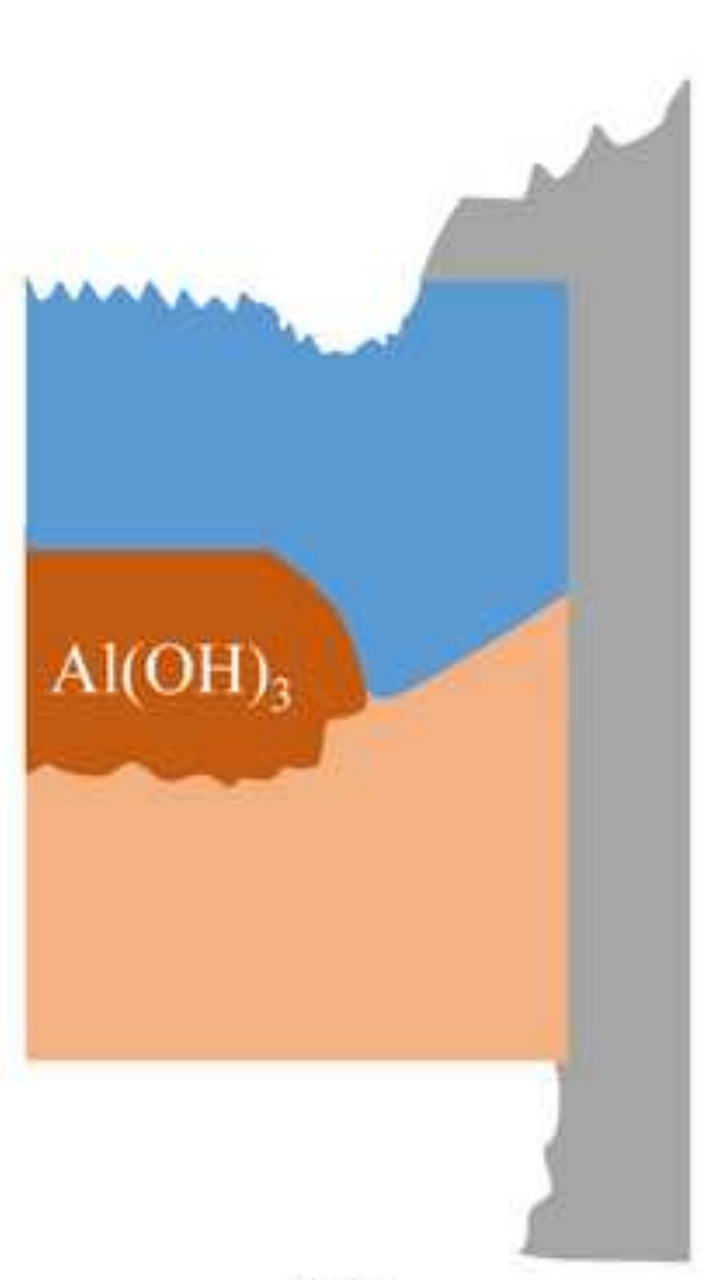

(c) 